\title{
Should be NICE have a Spanish NICE?
}

\author{
J. Feliu $\cdot$ E. Espinosa
}

Received: 17 April 2013/Accepted: 2 May 2013/Published online: 6 June 2013

(C) Federación de Sociedades Españolas de Oncología (FESEO) 2013

Cancer is the second leading cause of death in Spain, accounting for $25 \%$ of all deaths. One out of three men and one out of four women will have a cancer during their lives, a proportion that will increase with progressive ageing of the general population.

The direct cost of cancer in our country was $€ 3.8$ billion in 2002-2003, which represents $6.5 \%$ of the total health budget (59.3 billion) [1] and is similar to that of other European countries. The percentage ranges from 4.1 in Holland to $7 \%$ in Sweden, through $5.6 \%$ in UK and $5 \%$ in the USA [2]. However, the change over time is alarming: for instance, in the USA the direct medical expense of cancer has increased from about \$27 billion in 1990 to more than $\$ 90$ billion in 2008 [3]. There are no figures for Spain in this regard, although the expense has at least doubled. The main reason for this trend is the increasing cost of new drugs, the use of drugs in new indications and the incorporation of modern technologies to the clinic.

Cost escalation seems to be out of proportion considering the small benefit that brings in many instances. For example, the incorporation of new agents to the classical combination 5-fluorouracil and leucovorin in colorectal cancer has doubled survival, but at the expense of a 340-fold increase in cost [4]. As a result, therapy for the commonest types of cancer may mean $€ 30,000-60,000$ per drug and patient, with a minor impact on survival.

The inevitable question rises whether our society can afford increasing health costs. Considering also the current economical crisis, with national and regional restrictions as the norm, measures to guarantee the sustainability of the

J. Feliu $(\bowtie) \cdot$ E. Espinosa

Medical Oncology Service, La Paz Hospital, $\mathrm{P}^{\circ}$ de la Castellana, 261-28046 Madrid, Spain

e-mail: jaimefeliu@hotmail.com; jaime.feliu@salud.madrid.org health system are warranted. Doctors may contribute by prescribing according to treatment guidelines. We should select patients with higher chances of benefit, hence the need for progress in the field of predictive biomarkers. Likewise, treatments administered with low evidence of activity or in extreme situations should be avoided [5]. Independent investigation should be supported, particularly when evaluating new indications for conventional drugs and low-cost technologies. Thorough evaluation of new technologies should be performed to avoid those yielding a marginal benefit.

Along with above mentioned and other similar measures [3], cost streamlining and selective funding are the main factors that prevent overuse as a way to guarantee sustainability of the health system. The problem is how to achieve this and not produce inequality in a regionally fragmented health system. There are important differences in patient access to antineoplastic treatment in Spain, so some drugs are provided in some regions but not in others. Even if a drug has been approved for use in a given region, every single hospital has the legal authority to decide about its use, regardless of medical criteria. As a consequence, access to a given drug may be granted in a centre but denied in a nearby institution because of local economical constraints.

Considering this landscape, it would be reasonable to support the creation of a nation-wide agency to evaluate and decide about the financing of drugs, with binding effect on regional health systems and hospitals in terms of reimbursement, coverage level and price. This would avoid inequality and the need for re-evaluation at every region and every single hospital. In this regard, the National Institute for Health and Clinical Excellence (NICE) was set up in 1999 in the UK to reduce variation in the availability and quality of the British National Health System 
treatments and care [6]. Although this is a laudable proposal, the role of NICE has been highly controversial since its very beginning. Criticism mainly derives from the fact that its decisions reflect the cost-effectiveness of treatments, which is tightly linked to economical and political factors.

Clear criteria on the conditions for drug funding should be established to limit objections to a national agency of treatment evaluation. Not only statistically significant but also clinically significant differences should be detected between the new and the conventional treatment to grant public funding. There is no consensus about the definition of "clinically significant", but an absolute advantage of 3 months or a hazard ratio of 0.75 have been proposed for overall survival. In the case of progression-free survival, these figures would be 4-6 months and 0.5 , respectively [7]. These criteria may be too restrictive for conditions associated with a poor prognosis. For instance, if the estimated overall survival is less than 2 years, an improvement in progression-free survival of 3-4 months could be adequate [8], but even a shorter benefit could be acceptable if estimated survival is less than 1 year.

In addition to clinical benefit, treatment alternatives and cost should also be considered. The UK has developed a formal process for the evaluation of new technologies and drugs to guide health care financial coverage decisions, using cost-effective analysis (CEA) and quality-adjusted life years (QALYs). Other countries such as France, Canada or Australia also use CEA to decide about new approvals. Safety, mode of administration, seriousness of disease, absence of alternatives, quality of life or end-oflife issues could also be considered in addition to CEA [9, 10]. Scientific societies have been proposed as advisors to enhance and implement a rational approach to care decisions $[10,11]$. In Spain, the "Sociedad Española de Oncología Médica" (SEOM), among others, should take care of this responsibility.

The next step-the more complex-consists of deciding what monetary value is used to declare something as costeffective [11]. The amount has been arbitrarily established at $£ 30.000$ /QALY in the UK [12] and at values ranging from $\$ 50,000$ to $129,000 / \mathrm{QALY}$ in the USA (the former being the estimated cost of dialysis) [13]. The NICE has recently introduced the end-of-life criterion, which enables anticancer drugs to be valued more highly than other types of drugs [2].

It seems reasonable that the national health budget depends on the wealth of an individual country and, in fact, the WHO has proposed that highly cost-effective treatments would cost less than the per-capita gross national product (GNP), cost-effective $1-3 \times$ GNP, and cost- ineffective over this $3 \times$ threshold [14]. Using this criterion, the Netherlands has proposed $€ 80.000 / \mathrm{QALY}$ as the limit for cost-effectiveness [11]. In Spain, considering the current per-capita GNP, the limit would be established at $€ 70,000 / \mathrm{QALY}$. However, we should also listen what citizens have to say in this regard: a survey performed in the USA showed that most people would pay over $\$ 50,000$ for an additional life-year [15].

The whole process can work only if it is swift, dynamic and transparent. A thorough evaluation of new drugs requires considerable time and effort, but should be done quickly so patients under the indication can benefit as soon as possible and the interests of pharmaceutical companies are not harmed. Also, the corresponding budget should be granted upon drug approval so that all centres have access within indication. Otherwise we would be back into the current situation.

In conclusion, a resolute, thorough and clear debate should be done with participation of politicians, health care professionals, economists, experts in ethics and patients' representatives to agree on a cost-effectiveness threshold for new drugs and health technologies in our country. This agreement would be the base for a sustainable health system.

\section{References}

1. Jönsson B, Wilking N. A global comparison regarding patient access to cancer drugs. Ann Oncol. 2007;18(Suppl 3):1-77.

2. Sullivan R, Peppercorn J, Sikora K, Zalcberg J, Meropol N, Amir E, et al. Delivering affordable cancer care in high-income countries. Lancet Oncol. 2011;12:933-80

3. Elkin EB, Bach PB. Cancer's next frontier. Addressing high and increasing costs. JAMA. 2010;303:1086-7.

4. Schrag D. The price tag on progress: chemotherapy for colorectal cancer N Engl J Med. 2004;351:317-9.

5. Sánz-Ortiz J. Chemotherapy at the end of life: up until when? Clin Transl Oncol. 2012;14:667-74.

6. National Institute for Health and Care Excellence. http://www.nice.org.uk/ aboutnice/whoweare/who_we_are.jsp.

7. Ocana A, Tannock IF. When are "positive" clinical trials in oncology truly positive? J Natl Cancer Inst. 2011;103:16-20.

8. European Medicines Agency. Answers from the CHMP Scientific Advisory Group (SAG) for Oncology for revision of the anticancer guideline. EMA/ 768937/2012.

9. Pouvourville G. HAS to be NICE. Eur J Health Econ 2013 (in press).

10. Willemse PHB, Tjan-Heijnen VCG. Difficult decisions in the cost-effectiveness analysis of new cancer treatments. EJHPP. 2009;15:50-3.

11. Theriault RL. Health care cost: how do we decide value? When do we decide? How do we particularize the decisions? Oncologist. 2012;17:157-9.

12. Kirkdale R, Krell J, O'Hanlon C, Tuthill M, Waxman J. The cost of a QALY. QJ Med. 2010;103:715-20.

13. Fojo T, Grady C. How much is life worth: cetuximab non-small cell lung cancer, and the $\$ 440$ billion question. J Natl Cancer Inst. 2009;101:1044-8.

14. Murray CJ, Evans DB, Acharya A, Baltussen RM. Development of WHO guidelines on generalized cost-effectiveness analysis. Health Econ. 2000;9:235-51.

15. Braithwaite RS, Meltzer DO, King JT Jr, Leslie D, Roberts MS. What does the value of modern medicine say about the $\$ 50.000$ per quality-adjusted life-year decision rule? Med Care. 2008;46:349-56. 